\title{
A case of head injury
}

Sujit K. Bhattacharya*, Sudeshna Ganguly, Dipankar Bhattacharya and Sabahat Azim

Global Healthcare Systems Pvt. Ltd, 3B-207, Ecospace, Action Area II, CBD Rajarhat, New Town, Kolkata, India

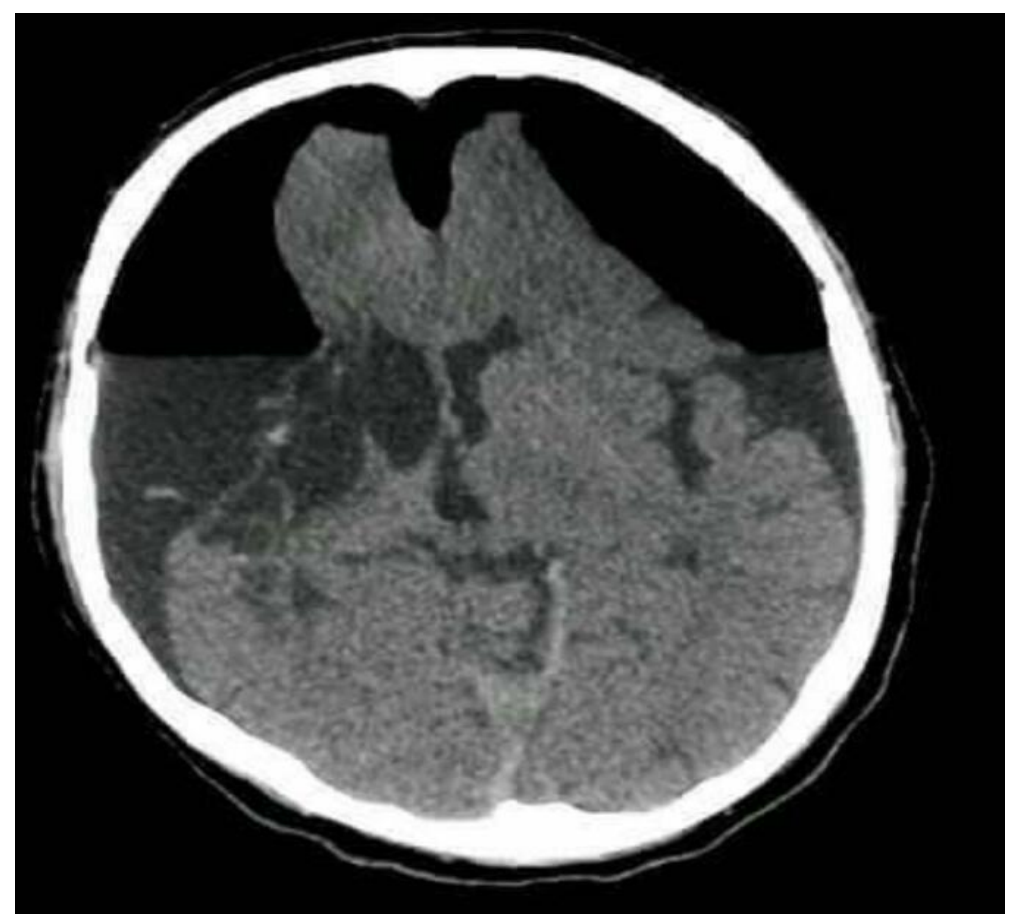

A patient with head injury due to Road Traffic Accident (RTA) presented to the emergency of Glocal Hospital, Krishnanagore, India. A CT scan of the Brain revealed a tension hydro-pneumo-cephalous with pressure effect on the brain from both sides due to rupture of frontal sinus.

Copyright: (C2017 Bhattacharya SK. This is an open-access article distributed under the terms of the Creative Commons Attribution License, which permits unrestricted use, distribution, and reproduction in any medium, provided the original author and source are credited.
Correspondence to: Sujit K. Bhattacharya, Global Healthcare Systems Pvt. Ltd, 3B-207, Ecospace, Action Area II, CBD Rajarhat, New Town, Kolkata, India, E-mail: sujitkbhattacharya@yahoo.com

Key words: head injury, RTA, CT scan, fluid, air

Received: August 09, 2017; Accepted: August 18, 2017; Published: August 21, 2017 